\title{
Examining validity of body mass index calculated using height and weight data from the US driver license
}

\author{
Alla Chernenko ${ }^{1 *} \mathbb{D}$, Huong Meeks ${ }^{2}$ and Ken R. Smith ${ }^{2,3}$
}

\begin{abstract}
Background: Driver license departments in many US states collect data on individuals' height and weight. These data can be useful to researchers in epidemiological and public health studies. As height and weight on driver license are self-reported, they may be prone to reporting bias. We compare height and weight obtained from driver license records and clinically measured height and weight, as well as body mass index (BMI) values calculated using the two data sources for the same individual.

Methods: We linked individual height and weight records obtained from the Driver License Division (DLD) in the Utah Department of Public Safety to clinical records from one of the largest healthcare providers in the state of Utah. We then calculated average differences between height, weight and BMI values separately for women and men in the sample, as well as discrepancies between the two sets of measures by age and BMI category. We examined how well self-reported height and weight from the driver licenses classify individuals into specific BMI categories based on clinical measures. Finally, we used two sets of BMI values to estimate individuals' relative risk of type II diabetes.
\end{abstract}

Results: Individuals, on average, tend to overestimate their height and underestimate their weight. Consequently, the value of BMI calculated using driver license records is lower than BMI calculated using clinical measurements. The discrepancy varies by age and by BMI category. Despite the discrepancy, BMI based on self-reported height and weight allows for accurate categorization of individuals at the higher end of the BMI scale, such as the obese. When used as predictors of relative risk of type II diabetes, both sets of BMI values yield similar risk estimates.

Conclusions: Data on height and weight from driver license data can be a useful asset for monitoring population health in states where such information is collected, despite the degree of misreporting associated with self-report.

Keywords: Body mass index, Self-report, Bias, Driver license

\section{Background}

Body mass index (BMI) is an important biometric measure commonly used across numerous disciplines to assess risk of many health conditions. Increased BMI is associated with excess health risks, including insulin resistance and hyperinsulinemia, Type II diabetes mellitus, hypertension, dyslipidemia, coronary heart disease, asthma, arthritis, gallbladder disease, several cancers, depression, as well as with increased all-cause mortality [1-8]. Individuals classified as

\footnotetext{
*Correspondence: alla.chernenko@utah.edu

${ }^{1}$ Department of Sociology, University of Utah, 390 South 1530 East, Rm 301,

Salt Lake City, UT 84112, USA

Full list of author information is available at the end of the article
}

underweight based on their BMI also experience heightened health and mortality risks and are likely to have poor psychological health $[4,5,9]$. While commonly used in clinical practice and public health research, BMI is not necessarily a perfect predictor of individual health. Multiple studies highlight limitations of BMI in certain subpopulations including children, teenagers, elderly and ethnic minority patients, and suggest the use of alternative anthropometric indicators. These include waist circumference, waist-to height ratio, waist-to-hip ratio, percent body fat, and fasting leptin levels, which may be more useful for predicting adiposity and associated health risks than BMI [7, 10-17]. Alternative anthropometric measures have been used to supplement 
BMI to refine health risk estimates within BMI categories [18].

One of the primary advantages of using BMI in population health research is not only its centrality to key biological pathways leading to crucial health outcomes, but also that it is relatively straightforward to measure. Many studies rely on self-reported height and weight to calculate BMI, and while these measures are prone to reporting biases, they are the best available option in larger-scale studies where direct measurement of height, weight or other anthropometric characteristics is difficult or prohibitively expensive.

Several studies document the existing discrepancies between self-reported height and weight and their clinically measured counterparts, as well as their derived BMI values [19-34]. Research demonstrates that individuals in general tend to overestimate their height and underestimate their weight, although the degree of discrepancy varies across different demographic categories. For example, increasing age is associated with more disagreement between self-reported and measured height and weight, likely due to changes in stature and body composition and illnesses common among older individuals $[19,20]$. Misreporting of weight also varies by ethnicity and is more prevalent for individuals at the lower and higher ends of the BMI spectrum [7, 20, 22, 23, 35-37]. In addition, certain behaviors and medical conditions can play a role, as individuals with a history of dieting may be more likely to underestimate their weight, while people with history of eating disorders are more accurate in their reporting compared to the general population $[20,38]$. Despite the discrepancies, several studies generally show high correlation and agreement when comparing self-reported and clinically measured values $[19,21$, 24, 32, 33, 39, 40]. Given the bias towards lower BMI values, the association between BMI and certain health and mortality risks is likely to be biased, perhaps underestimated, when BMI measure is derived from self-reported height and weight [39, 41]. Some authors suggest correcting for the measurement error when using BMI based on self-reported height and weight when estimating health and mortality risks, noting that although corrected BMI performs better than uncorrected BMI, these corrections do not eliminate the bias completely [42]. BMI derived from self-reported height and weight should be therefore treated with caution, yet it nonetheless remains an essential measure in epidemiological studies.

In the US, height and weight information is collected in many states by their respective driver license or motor vehicle departments. In some instances, these data offer researchers an opportunity to use height and weight data from the driving public for medical and public health investigations. Although access to driver license data in some states may be heavily restricted, it can be possible for public health researchers to obtain millions of individual records from appropriate governmental agencies responsible for maintaining the driver license records in different states $[43,44]$. Since height and weight information contained in the driver license records is self-reported, it is likely prone to errors relative to clinical measures similar to those found in surveys that too rely on self-reported anthropometric information. Ossiander, Emanuel, O'Brien and Malone [45] linked 480 records from women enrolled in a population-based cancer etiology study in Washington state to their driver license records. They reported high positive correlations for both height and weight reported on the driver license and when measured during the study, despite the average discrepancies of $0.28 \mathrm{~cm}$ for height and $5.8 \mathrm{~kg}$ for weight, generally with height being overestimated and weight being underestimated on the driver license. An earlier study of a sample of 140 Asian women in Hawaii found that individuals underestimated their weight by $4.74 \mathrm{~kg}$ and overestimated their height by $2.06 \mathrm{~cm}$ [46]. Morris et al. [47] used driver license data for the state of Oregon to estimate BMI at the Census block group level and compared the estimates to those obtained from the Oregon Behavioral Risk Factor Surveillance System (BRFSS) - a CDC statewide random-digit-dial telephone survey. Although BRFSS also relies on self-reported height and weight data, block group level obesity prevalence calculated based on the driver license data was 18\% lower than BRFFS for men and $31 \%$ lower for women. At the same time, average Census block group BMI estimates showed a more modest discrepancy of $2 \%$ for men and $5 \%$ for women, with values derived from the driver license data being lower than those obtained from BRFFS. The results of these studies suggest that although information about height and weight obtained from driver licenses introduce reporting errors, it is biased in a predictable manner, i.e. height is likely overestimated, weight is likely underestimated, and, consequently, BMI calculated using these height and weight values is underestimated.

In this study, we examined the disagreement between BMI calculated using height and weight measured clinically and captured in electronic medical records and BMI calculated using height and weight obtained from driver licenses in a large sample of Utah drivers. We then evaluated the utility of the driver license and clinically measured height and weight by estimating the relative risks of having Type II diabetes using the two alternative versions of BMI as predictors to assess the usefulness of driver license data on height and weight in public health studies.

\section{Methods}

\section{Data}

The height and weight data were obtained from two sources. First, we used height and weight data provided 
to the Utah Population Database (UPDB) by agreement from the Driver License Division (DLD) in the Utah Department of Public Safety. Annual updates of driver license information from the DLD are linked to the UPDB. Second, height and weight data were also available from the University of Utah Health Science Center (UUHSC) - one of the two largest healthcare providers in the state of Utah - which maintains all clinical records for patients seen at the UUHSC, including anthropometric measures. These UUHSC records are linked to the UPDB at the individual level and are updated every six months.

From the Utah Population Database (UPDB), we selected 33,354 individuals with height and weight data from Driver License Division and University of Utah Health Science Center. We then restricted the sample to individuals who had complete height and weight values from both DLD and UUHSC, BMI values calculated from both sources between 12 and $60 \mathrm{~kg} / \mathrm{m}^{2}$, and differences in height and weight values between two sources not exceeding $10 \mathrm{~cm}$ and $40 \mathrm{~kg}$ respectively. We selected the cut-off for the difference between self-reported and clinically measured height based on the literature [32]. We were not able to establish a weight difference cut-off the same way, and opted for a data-driven approach, eliminating cases where difference between self-reported and clinically measured weight values were four or more standard deviations away from the mean. Using these cut-off points, we were able to allow for variation in values, while omitting the more extreme differences.

We also required that the dates on which clinical height and weight were measured were within 365 days of the dates on which height and weight were reported on the driver license, excluding individuals with larger gaps between the dates the measurements were reported. Finally, we excluded individuals whose last available follow up dates in UPDB were less than one year from when the height and weight were measured by UUHSC. While some individuals in this category have been lost to follow up, others died within 365 days after their UUHSC visit, which means they may have been severely ill at the time of the visit, and the illness, in turn, may have affected their weight. The final study sample comprised 16,576 subjects.

\section{Analysis}

We generated sex-specific descriptive statistics for the sample to illustrate the height and weight characteristics in the DLD (height $t_{\mathrm{D}}$ and weight $\mathrm{D}_{\mathrm{D}}$ ) and clinical records (height $_{C}$ and weight ${ }_{C}$ ), as well as BMI values calculated using the height and weight from the two different sources $\left(\mathrm{BMI}_{\mathrm{D}}\right.$ and $\left.\mathrm{BMI}_{\mathrm{C}}\right)$. BMI categories are defined as follows: underweight $\left(\mathrm{BMI}<18.5 \mathrm{~kg} / \mathrm{m}^{2}\right)$, normal weight (BMI between 18.5 and $24.9 \mathrm{~kg} / \mathrm{m}^{2}$ ) overweight
(BMI between 25.0 and $29.9 \mathrm{~kg} / \mathrm{m}^{2}$ ), Class I (BMI between 30.0 and $34.9 \mathrm{~kg} / \mathrm{m}^{2}$ ) and Class II - Class III obesity combined (BMI $\left.\geq 35 \mathrm{~kg} / \mathrm{m}^{2}\right)$. Formal Class III obesity individuals were too few in number to be treated as a separate category.

We then calculated differences between the mean DLD and clinical height (height $t_{D}-$ height $_{C}$ ), DLD and clinical weight (weight $\mathrm{D}_{\mathrm{D}}-$ weight $_{\mathrm{C}}$ ), and the BMI values calculated using DLD and clinical sources $\left(\mathrm{BMI}_{\mathrm{D}}-\mathrm{BMI}_{\mathrm{C}}\right)$ overall and by Differences were calculated separately for individuals of different ages (based on age provided in DLD records) and different BMI categories (based on $\mathrm{BMI}_{\mathrm{c}}$ ). Negative difference values indicate underestimation in the DLD values compared to the clinical values obtained from the UUHSC, and positive difference values reflect overestimation in the DLD values. Paired Wilcoxon signed rank tests were used to evaluate the differences between mean height, weight and BMI. This allowed us to understand the extent of variation in misreporting of height and weight by age and BMI. In this case, the paired Wilcoxon signed rank tests were selected because, while the two sets of measures being compared were obtained from the same sample of individuals, the distribution of differences between the two sets of measures were not normally distributed, hence warranting a non-parametric test. We also established that the variances in the two sets of measures were unequal, with few exceptions.

Cross-classifications of $\mathrm{BMI}_{\mathrm{D}}$ and $\mathrm{BMI}_{\mathrm{C}}$ were performed to determine to what extent self-reported height and weight from the driver licenses allows to classify individuals into specific BMI categories. Finally, we used logistic regression models to estimate individuals' likelihood of having type II diabetes using $\mathrm{BMI}_{\mathrm{C}}$ and $\mathrm{BMI}_{\mathrm{D}}$ as key predictors and controlling for birth year, sex, level of education, race and ethnicity. Four models were estimated using continuous and categorical $\mathrm{BMI}_{C}$ and $\mathrm{BMI}_{\mathrm{D}}$ as predictors. Information on individuals' diabetes diagnosis were obtained from statewide inpatient discharge and ambulatory surgery records for individuals seen at UUHSC, all of which are linked to UPDB. All analyses were performed using $\mathrm{R}$ statistical software version 3.4 (https://www.r-project.org/).

\section{Results}

Descriptive characteristics of the sample are presented in Table 1. Among both men and women, average values of height as reported in the DLD records exceed those found in clinical records, and values of weight $t_{D}$ are smaller than values of weight ${ }_{C}$. Average height for women in our sample is $163.8 \mathrm{~cm}$ based on the clinical data, and $164.1 \mathrm{~cm}$ based on the DLD data. Average weight for women, as reported in the UUHSC data, is equal to $79.1 \mathrm{~kg}$, and their average weight based on the DLD records is $73.4 \mathrm{~kg}$. For men, average values of 
Table 1 Descriptive characteristics of the sample

\begin{tabular}{|c|c|c|c|c|}
\hline & \multicolumn{2}{|l|}{$\begin{array}{l}\text { Female } \\
(N=8905)\end{array}$} & \multicolumn{2}{|l|}{$\begin{array}{l}\text { Male } \\
(N=7671)\end{array}$} \\
\hline & DLD & Clinical & DLD & Clinical \\
\hline Height (cm) & $164.1 \pm 7.0$ & $163.8 \pm 7.0$ & $178.9 \pm 7.7$ & $178.4 \pm 7.7$ \\
\hline Weight (kg) & $73.4 \pm 18.5$ & $79.1 \pm 21.0$ & $91.6 \pm 20.2$ & $94.4 \pm 21.8$ \\
\hline BMI $\left(\mathrm{kg} / \mathrm{m}^{2}\right)$ & $27.3 \pm 6.7$ & $29.5 \pm 7.6$ & $28.6 \pm 5.7$ & $29.6 \pm 6.2$ \\
\hline \multicolumn{5}{|l|}{ BMI categories (\%) } \\
\hline Underweight & $231(2.6)$ & $191(2.1)$ & $51(0.7)$ & $48(0.6)$ \\
\hline Normal weight & $3741(42.0)$ & $2742(30.8)$ & $2035(26.5)$ & $1738(22.7)$ \\
\hline Overweight & $2387(26.8)$ & $2306(25.9)$ & 3032 (39.5) & $2762(36.0)$ \\
\hline Type I obesity & $1428(16.0)$ & $1718(19.3)$ & $1628(21.2)$ & $1814(23.6)$ \\
\hline Type II/III obesity & $1118(12.6)$ & 1948 (21.9) & $925(12.1)$ & $1309(17.1)$ \\
\hline Age (years) & $49.0 \pm 17.4$ & $49.3 \pm 17.4$ & $51.9 \pm 17.4$ & $52.2 \pm 17.4$ \\
\hline \multicolumn{5}{|l|}{ Race (\%) } \\
\hline White & 7764 (87.2) & & $6613(86.2)$ & \\
\hline Other & 497 (5.6) & & $415(5.4)$ & \\
\hline \multicolumn{5}{|l|}{ Ethnicity (\%) } \\
\hline Hispanic & $1300(14.6)$ & & $902(11.8)$ & \\
\hline Non-Hispanic & $5848(65.7)$ & & $5186(67.6)$ & \\
\hline \multicolumn{5}{|l|}{ Education (\%) } \\
\hline Less than high school & $590(6.6)$ & & 407 (5.3) & \\
\hline High school & $1798(20.2)$ & & $1301(17.0)$ & \\
\hline Some college & 1954 (21.9) & & 1455 (19.0) & \\
\hline College graduate & $961(10.8)$ & & $883(11.5)$ & \\
\hline Graduate/professional degree & $714(8.0)$ & & $1120(14.6)$ & \\
\hline
\end{tabular}

Note. Mean values and standard deviations are reported for continuous variables: height, weight, BMI and age. For categorical variables - categorical BMI, race and education - number of individuals in each category is reported and corresponding percentage is presented in parentheses

height $_{\mathrm{C}}$ and height $\mathrm{D}_{\mathrm{D}}$ are $178.4 \mathrm{~cm}$ and $178.9 \mathrm{~cm}$ accordingly, while average weight ${ }_{\mathrm{C}}$ for men is $94.4 \mathrm{~kg}$, compared to the average value of $91.6 \mathrm{~kg}$ for weight ${ }_{\mathrm{D}}$. Consequently, average $\mathrm{BMI}_{\mathrm{D}}$ calculated using the DLD records is lower than $\mathrm{BMI}_{\mathrm{C}}$ calculated using clinical records from the UUHSC for individuals in our sample. Among women the BMI discrepancy is equal to $-2.19 \mathrm{~kg} / \mathrm{m}^{2}$, while among men the difference between $\mathrm{BMI}_{\mathrm{D}}$ and $\mathrm{BMI}_{\mathrm{C}}$ is $-1.06 \mathrm{~kg} /$ $\mathrm{m}^{2}$. Sex-specific height, weight and BMI differences are statistically significant at $p \leq 0.001$.

Height, weight and BMI differences vary among individuals based on age and clinical BMI value (Fig. 1). For women in our sample, the difference between height ${ }_{\mathrm{D}}$ and height $_{C}$ appears to increase with age, with older women having, on average the largest difference between the values. Women between the ages of 25 and 34 overestimate their height $t_{\mathrm{D}}$, on average, by $0.13 \mathrm{~cm}$, while women 65 years old and older report height $t_{D}$ that exceeds their clinically measured height ${ }_{C}$ by $0.52 \mathrm{~cm}$. Average differences for other age group fall between these values, with the exception of women between the ages of 16 and 24, who underestimate their height by an average of $-0.6 \mathrm{~cm}$.
Women between the ages of 16 and 24 are also the only category, for whom the difference between average clinical and self-reported height values is not statistically significant. Conversely, younger women, on average, underestimate their weight on the driver license to a greater extent than older women, with those between the ages of 25 and 34 reporting weight $_{\mathrm{D}}$ values that are, on average, $6.98 \mathrm{~kg}$ lower than their clinically recorded weight ${ }_{C}$ values. The difference diminishes with age. A similar pattern is observed with regard to $B M I_{D}$ and $B M I_{C}$, with $B_{D} I_{D}-$ $\mathrm{BMI}_{\mathrm{C}}=-2.61 \mathrm{~kg} / \mathrm{m}^{2}$ for women between the ages of 25 and 34 , and $\mathrm{BMI}_{\mathrm{D}}-\mathrm{BMI}_{\mathrm{C}}=-1.32 \mathrm{~kg} / \mathrm{m}^{2}$ for women 65 years old and older, with average differences for the remaining age groups falling between the two extremes.

Among men, the largest differences between average height $_{D}$ and height ${ }_{C}$ are observed in ages 16 to 24 (height $_{\mathrm{D}}-$ height $_{\mathrm{C}}=0.63 \mathrm{~cm}$ ) and after age $65\left(\right.$ height $_{\mathrm{D}}-$ height $_{C}=0.68 \mathrm{~cm}$ ). At the same time, men in these age groups have the lowest differences between average weight $_{\mathrm{D}}$ and weight $\mathrm{C}(-1.45 \mathrm{~kg}$ for men between the ages of 16 and 24 and $-1.86 \mathrm{~kg}$ for men 65 and older). Those between the ages of 35 and 44 have the largest 


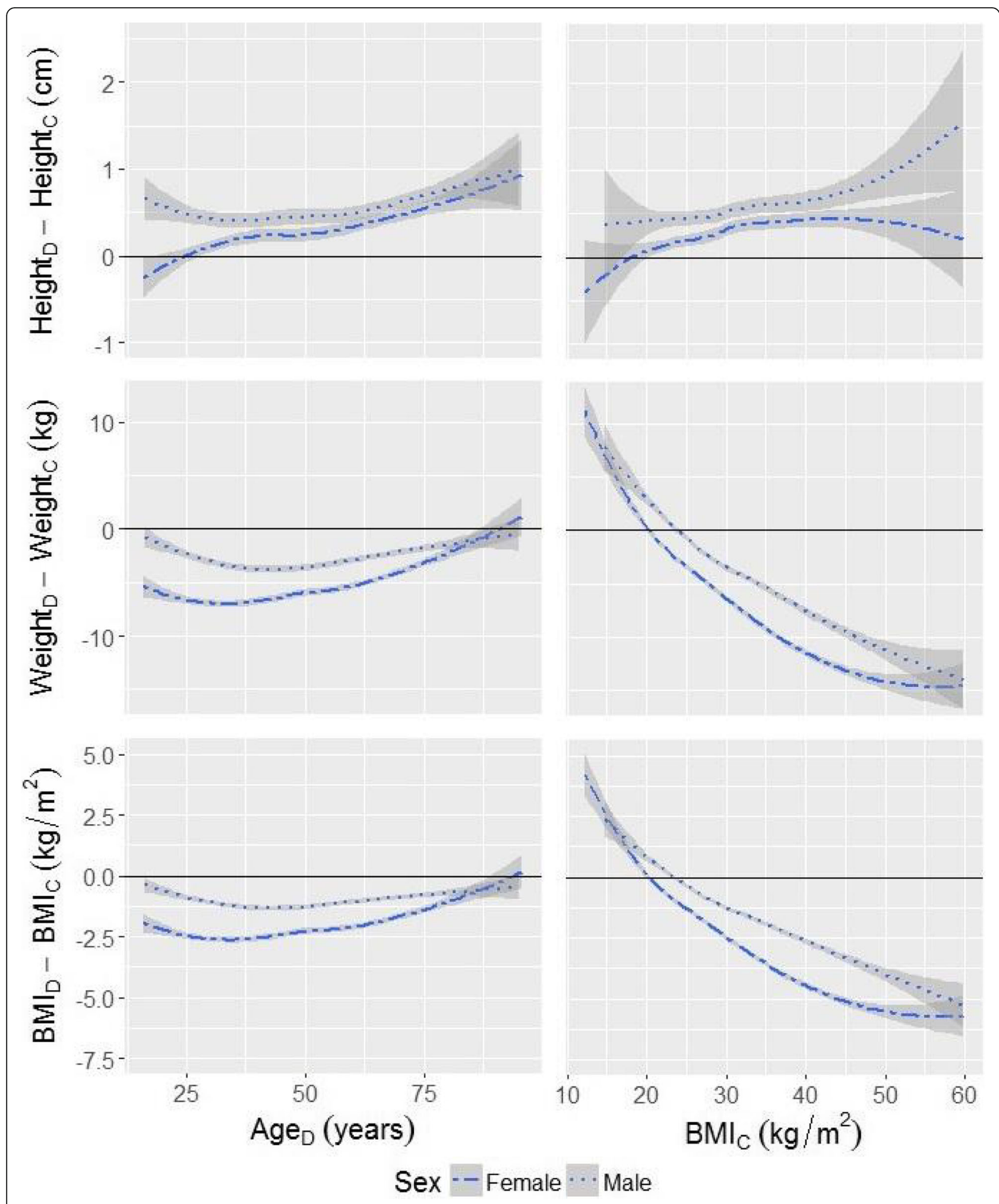

Fig. 1 Distribution of discrepancies between height, weight and BMI values obtained from the driver license records and clinically measured values by age and $\mathrm{BMI}_{\mathrm{C}}$ 
difference between average weight $t_{D}$ and weight $_{C}$, underestimating their weight by $3.91 \mathrm{~kg}$. Although the degree of misreporting varies, men tend to overestimate their height and underestimate their weight on driver license regardless of age group, which results in consistently lower values of $\mathrm{BMI}_{\mathrm{D}}$ compared to $\mathrm{BMI}_{\mathrm{C}}$. The largest difference is observed among men between the ages of 35 and $44\left(\mathrm{BMI}_{\mathrm{D}}-\mathrm{BMI}_{\mathrm{C}}=-1.38 \mathrm{~kg} / \mathrm{m}^{2}\right)$ and the smallest differences are found among those between the ages of 16 and $24\left(\mathrm{BMI}_{\mathrm{D}}-\mathrm{BMI}_{\mathrm{C}}=-0.62 \mathrm{~kg} / \mathrm{m}^{2}\right)$ and over the age of $65\left(\mathrm{BMI}_{\mathrm{D}}-\mathrm{BMI}_{\mathrm{C}}=-0.81 \mathrm{~kg} / \mathrm{m}^{2}\right)$. The magnitude of difference between self-reported and clinically measured height, weight and BMI values is smaller for men than for women.

Women at the lower end of the BMI range, as indicated by clinically measured height and weight values, have the smallest average difference between height ${ }_{\mathrm{D}}$ and height ${ }_{C}$ (height $_{D}-$ height $_{C}=0.08 \mathrm{~cm}$ for women classified as underweight), and those at the higher end of the BMI range have the highest difference (height ${ }_{\mathrm{D}}$ height $_{C}=0.42 \mathrm{~cm}$ for women classified as class II/III obese). When it comes to weight, the smallest average difference is observed among women in the normal weight range (weight ${ }_{D}-$ weight $_{C}=-1.57 \mathrm{~kg}$ ), and the difference increases with increasing BMI. Consequently, the discrepancy between $\mathrm{BMI}_{\mathrm{D}}$ and $\mathrm{BMI}_{\mathrm{C}}$ is also lowest for women whose BMI falls within the normal weight category $\left(\mathrm{BMI}_{\mathrm{D}}-\mathrm{BMI}_{\mathrm{C}}=-0.60 \mathrm{~kg} / \mathrm{m}^{2}\right)$ and highest among those at the higher end of the $\mathrm{BMI}$ range $\left(\mathrm{BMI}_{\mathrm{D}}\right.$ $-\mathrm{BMI}_{\mathrm{C}}=-2.95 \mathrm{~kg} / \mathrm{m}^{2}$ for women classified as type II/ III obese). Women at the lower end of the BMI range those classified as underweight - are an exception, as they tend to overestimate their weight and their $\mathrm{BMI}_{\mathrm{D}}$ value is, on average, higher than their $\mathrm{BMI}_{C}$ value. The distribution of difference between self-reported and clinical values is similar for men in that the lowest differences are found among those who fall within the normal weight range $\left(\right.$ height $_{D}-$ height $_{C}=0.42 \mathrm{~cm}$, weight $_{D}-$ weight $_{C}=0.87 \mathrm{~kg}, \mathrm{BMI}_{\mathrm{D}}-\mathrm{BMI}_{\mathrm{C}}=0.16 \mathrm{~kg} / \mathrm{m}^{2}$ ) and the differences increase with increasing BMI. Again, similarly to women, men at the lower end of the BMI range overreport their weight, which results in inflated value of $\mathrm{BMI}_{\mathrm{D}}$. The magnitude of difference between self-reported and clinical values for these men is comparable to the difference observed for those classified as class I obese based on their $\mathrm{BMI}_{\mathrm{C}}$.

Cross-classification of categorical $\mathrm{BMI}_{\mathrm{D}}$ and $\mathrm{BMI}_{\mathrm{C}}$, along with corresponding sensitivity and specificity statistics for each $B M I_{D}$ category, and positive and negative predictive values are presented in Table 2. Among women, $94.4 \%$ of those categorized as class II/III obese based on their $\mathrm{BMI}_{\mathrm{D}}$ also fall within this category based on their $\mathrm{BMI}_{\mathrm{C}}$ (sensitivity $=0.542$, specificity $=0.991$ ). This indicates that there is a $94.4 \%$ probability that a woman classified as class II/III obese based on her $\mathrm{BMI}_{\mathrm{D}}$ is also considered class $\mathrm{II} / \mathrm{III}$ obese based on her $\mathrm{BMI}_{\mathrm{C}}$. Based on the negative predictive value calculated for this group, $88.5 \%$ of women not assigned to the class II/III obesity category based on their $\mathrm{BMI}_{\mathrm{D}}$ also do not fall within this category based on their $\mathrm{BMI}_{\mathrm{C}}$. While we can assign a $\mathrm{BMI}$ category most accurately to class II/III women, the classification is least accurate for women classified as underweight based on their $\mathrm{BMI}_{\mathrm{D}}$. Only $45.9 \%$ of women with $\mathrm{BMI}_{\mathrm{D}}$ in the underweight range also have $\mathrm{BMI}_{\mathrm{C}}$ in the underweight range (sensitivity $=0.555$, specificity $=0.986$ ). At the same time, negative predictive value is the highest for this category: $99.0 \%$ of women not considered underweight based on their $\mathrm{BMI}_{\mathrm{D}}$ are also not underweight according to their $\mathrm{BMI}_{\mathrm{C}}$. For the women classified as normal weight, overweight and class I obese based on their $\mathrm{BMI}_{\mathrm{D}}$, we can correctly classify $66.6 \%$ (sensitivity $=0.909$, specificity $=0.797$ ), $51.9 \%$ (sensitivity $=0.537$, specificity $=0.826$ ) and $48.5 \%$ (sensitivity $=0.403$, specificity $=0.898$ ), respectively.

Similarly, among men, the best agreement is observed in the class II/III obesity category: $91.0 \%$ of men whose $\mathrm{BMI}_{\mathrm{D}}$ falls within the class II/III obesity range also have $\mathrm{BMI}_{C}$ values within the same range (sensitivity $=0.643$, specificity $=0.987$ ). There is also a relatively high negative predictive value for this category (0.931). The classification is least accurate for men whose $\mathrm{BMI}_{\mathrm{D}}$ places them in the underweight category: $49.0 \%$ of these men are also classified as underweight based on their $\mathrm{BMI}_{\mathrm{C}}$ (sensitivity= 0.490 , specificity $=0.997$ ). This category also has the highest negative predictive value: $99.7 \%$ of men with $\mathrm{BMI}_{\mathrm{D}}$ not falling within the underweight range are also not considered underweight based on their $\mathrm{BMI}_{\mathrm{C}}$. For men in the normal weight, overweight and class I obesity categories, percentages of individuals classified correctly are $73.0 \%$ (sensitivity $=0.855$, specificity $=0.908), 70.3 \%$ (sensitivity $=0.771$, specificity $=0.816$ ) and $65.4 \%$ (sensitivity $=0.587$, specificity $=0.904$ ), respectively.

Despite the discrepancies between height and weight values obtained from the DLD and clinically measured height and weight values, as well as BMI calculated using different data sources, $\mathrm{BMI}_{C}$ and $\mathrm{BMI}_{\mathrm{D}}$ yield similar results when used as relative risk predictors in logistic regression models (Table 3). In Models 1 and 2 we used continuous variables for $\mathrm{BMI}_{C}$ and $\mathrm{BMI}_{\mathrm{D}}$ respectively to estimate relative risk of type II diabetes. Type II diabetes diagnosis is present in in 2603 or $29 \%$ of women and 2818 or about $37 \%$ of men in our sample. The coefficients of interest in the models are very similar, with both $\mathrm{BMI}_{\mathrm{C}}$ and $\mathrm{BMI}_{\mathrm{D}}$ associated with a two-fold increase in relative risk of type II diabetes for a unit increase in BMI (Model $1 \mathrm{RR}=2.04$, 95\% CI 1.962.12; Model $2 \mathrm{RR}=2.09,95 \%$ CI 2.01-2.18). When BMI is measured using four categories (underweight, normal weight, overweight, type I obesity and type II/III obesity) 
Table 2 Cross-classification of $\mathrm{BMI}_{\mathrm{D}}$ and $\mathrm{BMI}_{C}$ for standard $\mathrm{BMI}$ categories

\begin{tabular}{|c|c|c|c|c|c|}
\hline & \multicolumn{5}{|l|}{$B M I_{C}(\%)$} \\
\hline & Underweight & Normal weight & Overweight & Class I obesity & Class II/III obesity \\
\hline \multicolumn{6}{|l|}{ Female } \\
\hline \multicolumn{6}{|l|}{$B M I_{D}$ category } \\
\hline Underweight & $106(45.9)$ & $117(50.6)$ & $7(3.0)$ & $1(0.4)$ & $0(0.0)$ \\
\hline Normal weight & $76(2.0)$ & $2491(66.6)$ & 959 (25.6) & $185(4.9)$ & $30(0.8)$ \\
\hline Overweight & $7(0.3)$ & $127(5.3)$ & $1239(51.9)$ & $785(32.9)$ & $229(9.6)$ \\
\hline Class I obesity & $2(0.1)$ & $6(0.4)$ & $94(6.6)$ & $692(48.5)$ & $634(44.4)$ \\
\hline Class II/III obesity & $0(0.0)$ & $1(0.1)$ & $7(0.6)$ & $55(4.9)$ & $1055(94.4)$ \\
\hline Sensitivity & 0.555 & 0.909 & 0.537 & 0.403 & 0.542 \\
\hline Specificity & 0.986 & 0.797 & 0.826 & 0.898 & 0.991 \\
\hline Pos. predictive value & 0.459 & 0.666 & 0.519 & 0.485 & 0.944 \\
\hline Neg. predictive value & 0.990 & 0.951 & 0.836 & 0.863 & 0.885 \\
\hline \multicolumn{6}{|l|}{ Male } \\
\hline \multicolumn{6}{|l|}{$B M I_{D}$ category } \\
\hline Underweight & $25(49.0)$ & $22(43.1)$ & $4(7.8)$ & $0(0.0)$ & $0(0.0)$ \\
\hline Normal weight & $22(1.1)$ & $1486(73.0)$ & $484(23.8)$ & $41(0.2)$ & $2(0.1)$ \\
\hline Overweight & $1(0.0)$ & $219(7.2)$ & $2130(70.3)$ & $637(21.0)$ & $45(1.5)$ \\
\hline Class I obesity & $0(0.0)$ & $11(0.7)$ & $133(8.2)$ & $1064(65.4)$ & $420(25.8)$ \\
\hline Class II/III obesity & $0(0.0)$ & $0(0.0)$ & $11(1.2)$ & $72(7.8)$ & $842(91.0)$ \\
\hline Sensitivity & 0.521 & 0.855 & 0.771 & 0.587 & 0.643 \\
\hline Specificity & 0.997 & 0.908 & 0.816 & 0.904 & 0.987 \\
\hline Pos. predictive value & 0.490 & 0.730 & 0.703 & 0.654 & 0.910 \\
\hline Neg. predictive value & 0.997 & 0.955 & 0.864 & 0.876 & 0.931 \\
\hline
\end{tabular}

Note. Subscript ${ }_{C}$ is used to denote BMI calculated using the clinical height and weight values. Subscript ${ }_{D}$ is used to denote BMI calculated using the height and weight values obtained from the DLD

in Models 3 and 4, relative risk of type II diabetes is associated with progressively higher BMI categories. In Model 3 that uses $\mathrm{BMI}_{\mathrm{C}}$, the relative risks for overweight, type I obesity and type II/III obesity are 1.82 (95\% CI: 1.62-2.03), 3.47 (95\% CI 3.09-3.90) and 6.78 (95\% CI 6.02-7.63), respectively, compared to the reference category - individuals whose BMI falls within a normal weight range. Model 4 , which analyzes $\mathrm{BMI}_{\mathrm{D}}$ shows similar results, with relative risks of 2.15 (95\% CI 1.94-2.37), 4.18 (95\% CI 3.74-4.67) and 8.07 (95\% CI 7.13-9.14) for individuals in overweight, type I obesity and type II/III obesity categories, respectively. In both Model 3 and Model 4, underweight individuals have lower relative risks of type II diabetes compared to the reference category. Relative risks of type II diabetes estimated using $\mathrm{BMI}_{\mathrm{C}}$ and $\mathrm{BMI}_{\mathrm{D}}$ for underweight individuals are $0.54(95 \% \mathrm{CI} 0.33-0.89)$ and 0.58 (95\% CI $0.36-0.92)$ respectively.

\section{Discussion}

In our sample, self-reported height and weight differ from clinically measured values in a predictable manner: individuals, on average, overestimate their height and underestimate their weight, resulting in significant differences between $B M I_{D}$ using height and weight values from the driver license and $\mathrm{BMI}_{C}$ using clinically measured height and weight. For women, the difference between $B M I_{D}$ and $B M I_{C}$ is equal to $-2.19 \mathrm{~kg} / \mathrm{m}^{2}$, and for men, the difference is equal to $-1.06 \mathrm{~kg} / \mathrm{m}^{2}$. These results are consistent with previous findings indicating consistent underestimation of BMI based on self-reported height and weight values $[21,22,24,25$, 30, 31, 35].

The discrepancy between $\mathrm{BMI}_{\mathrm{D}}$ and $\mathrm{BMI}_{\mathrm{C}}$ is significant across age and $\mathrm{BMI}_{\mathrm{C}}$ categories, although there is variation between groups. Among women, the difference between $\mathrm{BMI}_{\mathrm{D}}$ and $\mathrm{BMI}_{\mathrm{C}}$ values is greatest between the ages of 25 and 34, and among men it is greatest between the ages of 35 and 44. For women, the average difference between $\mathrm{BMI}_{\mathrm{D}}$ and $\mathrm{BMI}_{\mathrm{C}}$ decreases with age, while the relationship between age and BMI discrepancy for men is U-shaped. The smallest average BMI discrepancies are found for women aged 65 and older and, among men, for those aged 16 to 24 and aged 65 and older. Previous 


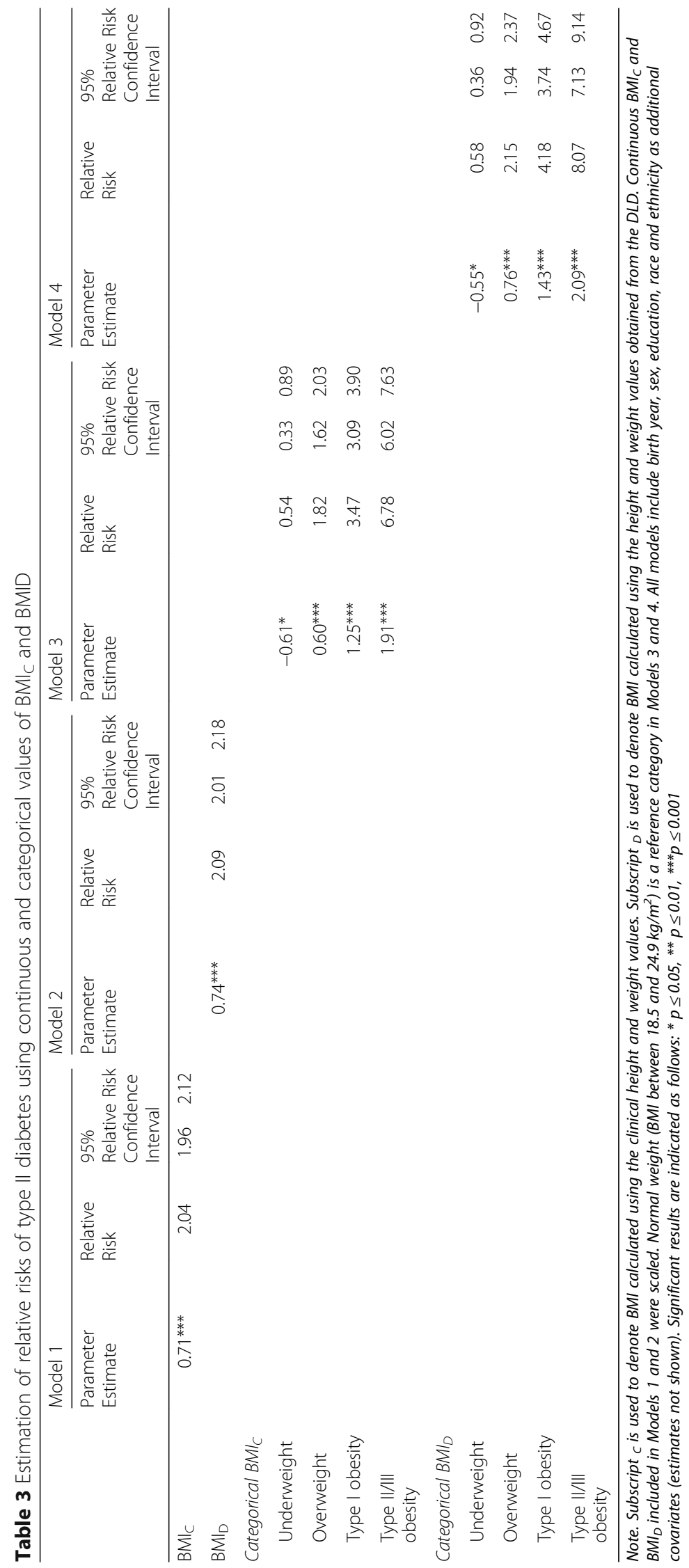


studies suggest that the discrepancy between self-reported and clinically measured BMI value increases with age $[19,20]$, which differs from our results. When it comes to distribution of discrepancy across $\mathrm{BMI}_{\mathrm{C}}$ values, the largest differences between $\mathrm{BMI}_{\mathrm{D}}$ and $\mathrm{BMI}_{\mathrm{C}}$ are found at the extreme end of the $\mathrm{BMI}_{\mathrm{C}}$ scale: $\mathrm{BMI}_{\mathrm{D}}-\mathrm{BMI}_{\mathrm{C}}$ is equal to $-4.48 \mathrm{~kg} / \mathrm{m}^{2}$ for class $\mathrm{II} / \mathrm{III}$ obese women and $-1.32 \mathrm{~kg} / \mathrm{m}^{2}$ for class II/III obese men. This finding is consistent with previous studies showing the greatest weight and BMI underestimation at higher values of BMI [7, 20, 22, 23, 35-37].

$\mathrm{BMI}_{\mathrm{D}}$ obtained from driver license records allows for fairly accurate classification into $\mathrm{BMI}_{\mathrm{C}}$ category for class II/III obese individuals. Although classification is less successful in the remaining BMI categories, the pattern of misclassification exhibits regularity: for each category, those that are misclassified tend to fall in the next highest category. For example, $66.6 \%$ of women who are considered normal weight based on their $\mathrm{BMI}_{\mathrm{D}}$ are also assigned into the normal weight category based on their $\mathrm{BMI}_{\mathrm{C}}$. Of those that remain, the majority are assigned into the overweight category - one category above normal weight. Similarly, we can correctly classify $51.9 \%$ of women whose $\mathrm{BMI}_{\mathrm{D}}$ falls within the overweight range, and the majority of those not classified correctly are in the class I obesity category based on their $\mathrm{BMI}_{\mathrm{C}}$. Because of this misclassification pattern, we can accurately classify individuals not only to the class II/III obesity category, but also to a combined obesity category, which includes class I and class II/III obese individuals (BMI $\geq$ $30.0 \mathrm{~kg} / \mathrm{m}^{2}$ ). When treating class I and class II/III obesity as separate categories, we are able to correctly classify $48.5 \%$ of women and $65.4 \%$ of men whose $\mathrm{BMI}_{\mathrm{D}}$ falls within the class I obesity range. However, for both men and women, the majority of those misclassified are in the class II/III obesity category. Consequently, when combining the two categories we can achieve positive predictive values of 0.957 for women and 0.939 for men. We conclude that although $\mathrm{BMI}_{\mathrm{D}}$ does not allow for very accurate classification of individuals in the underweight, normal weight and overweight categories, it can be particularly useful for BMI categorization at the high end of the BMI scale.

To assess predictive utility of $\mathrm{BMI}_{\mathrm{D}}$ and $\mathrm{BMI}_{\mathrm{C}}$, we estimated relative risks of type II diabetes using continuous and categorical versions of $\mathrm{BMI}_{\mathrm{D}}$ and $\mathrm{BMI}_{\mathrm{C}}$. In models with continuous predictors, relative risk estimates associated with $\mathrm{BMI}_{\mathrm{D}}$ and $\mathrm{BMI}_{\mathrm{C}}$ are remarkably similar: an equal increase in $\mathrm{BMI}_{\mathrm{D}}$ and $\mathrm{BMI}_{\mathrm{C}}$ is associated with a two-fold increase in relative risk of type II diabetes. When treated as categorical predictors, $\mathrm{BMI}_{\mathrm{D}}$ and $\mathrm{BMI}_{\mathrm{C}}$ also behave similarly: those in the underweight category experience reduction of relative risks of having a condition relative to those classified as normal weight, and risks are progressively greater in the overweight, class I obese and class II/III obese individuals. For these three categories, relative risks estimated using $\mathrm{BMI}_{\mathrm{D}}$ are somewhat higher compared to those estimated using $\mathrm{BMI}_{\mathrm{C}}$, but $95 \%$ confidence intervals overlap. Larger relative risk estimates for the model with a categorical $\mathrm{BMI}_{\mathrm{D}}$ predictor can be partially explained by the pattern of BMI misclassification observed in the data. Our models indicate that $\mathrm{BMI}_{\mathrm{D}}$ obtained from driver license records is comparable to clinically measured $\mathrm{BMI}_{\mathrm{C}}$ when used as a predictor of type II diabetes. Furthermore, relative risks estimates calculated using $\mathrm{BMI}_{\mathrm{C}}$ are more conservative compared to those calculated using $\mathrm{BMI}_{\mathrm{D}}$. Comparable analyses of other health outcomes that are associated with BMI and with data from different populations can help further validate the value of using driver license data for assessing health risks.

It is important to acknowledge that although we assume that clinically recorded height and weight values more accurately reflect individuals' true height and weight, clinical records are susceptible to measurement error as well. It is not possible to determine whether the patients were asked to remove shoes and clothing when their height and weight were recorded. In addition, one must be cautious when generalizing results of the present study to other populations, in particular, populations with greater degree of racial and ethnic diversity. Individuals in our sample are predominantly white, and height and weight misreporting vary by ethnicity [7, 20, $23,36,37]$. Finally, by relying on a major medical provider as a source of clinical height and weight measurements, we are likely systematically omitting a portion of the population with limited access to health services, i.e. un- and under-insured and lower income individuals. Socioeconomic status may influence one's perception of own body, which, in turn, can affect the degree of weight misreporting [37].

\section{Conclusions}

We demonstrate that self-reported height and weight data obtained from the driver license records differ systematically from clinically measured height and weight. The differences result in BMI calculated using the driver license data being lower than clinically measured BMI. BMI based on driver license records allows for accurate classification of individuals for those categorized as obese, and performs similarly to clinically measured BMI as a predictor of relative risk of type II diabetes mellitus. We conclude that driver license height and weight data can be a useful asset for monitoring population health. States that do not currently collect height and weight information during the driver license application process may consider establishing a procedure for doing so, as it would allow for more efficient monitoring of population health. 


\section{Abbreviations}

BMI: Body Mass Index; BRFSS: Behavioral Risk Factor Surveillance System; DLD: Driver License Division; UPDB: Utah Population Database;

UUHSC: University of Utah Health Science Center

\section{Acknowledgements}

Not applicable.

\section{Funding}

We thank the Pedigree and Population Resource of the Huntsman Cancer Institute, University of Utah (funded in part by the Huntsman Cancer Foundation) for its role in the ongoing collection, maintenance and support of the Utah Population Database (UPDB). We also acknowledge partial support for the UPDB through grant P30 CA2014 from the National Cancer Institute, University of Utah and from the University of Utah's Program in Personalized Health and Center for Clinical and Translational Science, as well as partial support for this study through National Institutes of Health grant R21 DK080406 (Neighborhood Characteristics and Body Mass Index Selection or Causation?: Contact PI Smith).

\section{Availability of data and materials}

Special attention is given to protect individuals and their information contained within the UPDB and the organizations that contribute data while also allowing access to researchers. Accordingly, the Utah Resource for Genetic and Epidemiologic Research (RGE), established in 1982 by Executive Order of the Governor of Utah, administers access to the UPDB through a review process of all proposals using UPDB data. The protection of privacy and confidentiality of individuals represented in these records has been negotiated with agreements between RGE and data contributors. Data from the UPDB is available only for approved health-related research studies and access is project-specific and granted after review and approval by an RGE oversight committee and the University of Utah's IRB. This process allows researchers with approved protocols to use the data, a process that has proven effective and successful as evidenced by hundreds of approved studies that have relied on the UPDB. Any proposed re-use of the data that are the basis of this this paper are available subject to RGE and IRB approval as described here.

\section{Authors contributions}

AC contributed to the analysis and interpretation of data and drafted the manuscript. HM contributed to dataset construction and data analysis. KRS conceptualized the study and supervised the project. All authors critically revised the manuscript and approved the final version before submission.

\section{Ethics approval and consent to participate}

The use of records in this project has been approved by the University of Utah's Resource for Genetic and Epidemiologic Research (RGE) and the Institutional Review Board.

\section{Consent for publication}

Not applicable.

\section{Competing interests}

The authors declare that they have no competing interests.

\section{Publisher's Note}

Springer Nature remains neutral with regard to jurisdictional claims in published maps and institutional affiliations.

\section{Author details}

'Department of Sociology, University of Utah, 390 South 1530 East, Rm 301, Salt Lake City, UT 84112, USA. ²Population Sciences, Huntsman Cancer Institute, University of Utah, 2000 Circle of Hope, Salt Lake City, UT 84112, USA. ${ }^{3}$ Department of Family and Consumer Studies, University of Utah, 225 South 1400 East Alfred Emery Building 228, Salt Lake City, UT 84112, USA.
Received: 28 June 2018 Accepted: 3 January 2019

Published online: 22 January 2019

\section{References}

1. Must A, Spadano J, Coakley EH, Field AE, Colditz G, Dietz WH. The disease burden associated with overweight and obesity. Jama. 1999:282(16):1523-9.

2. Mokdad AH, Bowman BA, Ford ES, Vinicor F, Marks JS, Koplan JP. The continuing epidemics of obesity and diabetes in the United States. Jama. 2001:286(10):1195-200

3. Pi-Sunyer FX. The obesity epidemic: pathophysiology and consequences of obesity. Obesity. 2002;10(S12).

4. Ali SM, Lindström M. Socioeconomic, psychosocial, behavioural, and psychological determinants of BMI among young women: differing patterns for underweight and overweight/obesity. Eur J Pub Health. 2006;16(3):324-30.

5. Flegal KM, Graubard BI, Williamson DF, Gail MH. Excess deaths associated with underweight, overweight, and obesity. Jama. 2005;293(15):1861-7.

6. Hu FB. Overweight and obesity in women: health risks and consequences. J Women's Health. 2003;12(2):163-72.

7. Stommel M, Schoenborn CA. Variations in BMI and prevalence of health risks in diverse racial and ethnic populations. Obesity. 2010;18(9):1821-6.

8. Luppino FS, de Wit LM, Bouvy PF, Stijnen T, Cuijpers P, Penninx BW, Zitman FG. Overweight, obesity, and depression: a systematic review and metaanalysis of longitudinal studies. Arch Gen Psychiatry. 2010;67(3):220-9.

9. Katzmarzyk PT, Craig CL, Bouchard C. Original article underweight, overweight and obesity: relationships with mortality in the 13-year followup of the Canada fitness survey. J Clin Epidemiol. 2001;54(9):916-20.

10. Savva S, Tornaritis M, Savva M, Kourides Y, Panagi A, Silikiotou N, Georgiou C, Kafatos A. Waist circumference and waist-to-height ratio are better predictors of cardiovascular disease risk factors in children than body mass index. Int J Obes. 2000:24(11):1453.

11. Frankenfield DC, Rowe WA, Cooney RN, Smith JS, Becker D. Limits of body mass index to detect obesity and predict body composition. Nutrition. 2001;17(1):26-30.

12. Shah NR, Braverman ER. Measuring adiposity in patients: the utility of body mass index (BMI), percent body fat, and leptin. PLoS One. 2012;7(4):e33308.

13. Ode JJ, Pivarnik JM, Reeves MJ, Knous JL. Body mass index as a predictor of percent fat in college athletes and nonathletes. Med Sci Sports Exerc. 2007; 39(3):403-9.

14. Romero-Corral A, Somers VK, Sierra-Johnson J, Thomas RJ, Collazo-Clavell M, Korinek J, Allison TG, Batsis J, Sert-Kuniyoshi F, Lopez-Jimenez F. Accuracy of body mass index in diagnosing obesity in the adult general population. Int J Obes. 2008;32(6):959-66.

15. Rothman KJ. BMI-related errors in the measurement of obesity. Int J Obes. 2008;32:S56-9.

16. Ashwell M, Gunn P, Gibson S. Waist-to-height ratio is a better screening too than waist circumference and BMI for adult cardiometabolic risk factors: systematic review and meta-analysis. Obes Rev. 2012;13(3):275-86.

17. Dudeja V, Misra A, Pandey R, Devina G, Kumar G, Vikram N. BMI does not accurately predict overweight in Asian Indians in northern India. Br J Nutr. 2001;86(1):105-12.

18. Janssen I, Katzmarzyk PT, Ross R. Body mass index, waist circumference, and health risk: evidence in support of current National Institutes of Health guidelines. Arch Intern Med. 2002;162(18):2074-9.

19. Kuczmarski MF, Kuczmarski RJ, Najjar M. Effects of age on validity of selfreported height, weight, and body mass index: findings from the third National Health and nutrition examination survey, 1988-1994. J Am Diet Assoc. 2001;101(1):28-34.

20. Villanueva EV. The validity of self-reported weight in US adults: a population based cross-sectional study. BMC Public Health. 2001;1(1):1.

21. Huber LRB. Validity of self-reported height and weight in women of reproductive age. Matern Child Health J. 2007;11(2):137-44.

22. Dekkers JC, van Wier MF, Hendriksen IJ, Twisk JW, van Mechelen W. Accuracy of self-reported body weight, height and waist circumference in a Dutch overweight working population. BMC Med Res Methodol. 2008:8(1):69.

23. Stommel M, Schoenborn CA. Accuracy and usefulness of BMI measures based on self-reported weight and height: findings from the NHANES \& NHIS 2001-2006. BMC Public Health. 2009;9(1):1.

24. Ng SP, Korda R, Clements M, Latz I, Bauman A, Bambrick H, Liu B, Rogers K, Herbert N, Banks E. Validity of self-reported height and weight and derived 
body mass index in middle-aged and elderly individuals in Australia. Aust $\mathrm{N}$ Z J Public Health. 2011;35(6):557-63.

25. Vuksanović M, Safer A, Palm F, Stieglbauer G, Grau A, Becher H. Validity of self-reported BMI in older adults and an adjustment model. J Public Health. 2014;22(3):257-63.

26. Niedźwiedzka E, Długosz A, Wądołowska L. Validity of self-reported height and weight in elderly poles. Nutr Res Pract. 2015;9(3):319-27.

27. Gorber SC, Tremblay M, Moher D, Gorber B. A comparison of direct vs. selfreport measures for assessing height, weight and body mass index: a systematic review. Obes Rev. 2007;8(4):307-26.

28. Engstrom JL, Paterson SA, Doherty A, Trabulsi M, Speer KL. Accuracy of selfreported height and weight in women: an integrative review of the literature. J Midwifery Womens Health. 2003;48(5):338-45.

29. Craig BM, Adams AK. Accuracy of body mass index categories based on self-reported height and weight among women in the United States. Matern Child Health J. 2009;13(4):489-96.

30. Bolton-Smith C, Woodward M, Tunstall-Pedoe H, Morrison C. Accuracy of the estimated prevalence of obesity from self reported height and weight in an adult Scottish population. J Epidemiol Community Health. 2000;54(2): $143-8$.

31. Niedhammer I, Bugel I, Bonenfant S, Goldberg M, Leclerc A. Validity of selfreported weight and height in the French GAZEL cohort. Int I Obes. 2000; 24(9):1111.

32. Spencer EA, Appleby PN, Davey GK, Key TJ. Validity of self-reported height and weight in 4808 EPIC-Oxford participants. Public Health Nutr. 2002;5(4): $561-5$.

33. Wada K, Tamakoshi K, Tsunekawa T, Otsuka R, Zhang H, Murata C, Nagasawa $\mathrm{N}$, Matsushita K, Sugiura K, Yatsuya H. Validity of self-reported height and weight in a Japanese workplace population. Int J Obes. 2005;29(9):1093.

34. Santillan A, Camargo C. Body mass index and asthma among Mexican adults: the effect of using self-reported vs measured weight and height. Int J Obes. 2003;27(11):1430.

35. Shiely F, Perry IJ, Lutomski J, Harrington J, Kelleher CC, McGee H, Hayes K. Temporal trends in misclassification patterns of measured and self-report based body mass index categories-findings from three population surveys in Ireland. BMC Public Health. 2010;10(1):1.

36. Gillum RF, Sempos CT. Ethnic variation in validity of classification of overweight and obesity using self-reported weight and height in American women and men: the third National Health and nutrition examination survey. Nutr J. 2005;4(1):27.

37. Paeratakul S, White MA, Williamson DA, Ryan DH, Bray GA. Sex, race/ ethnicity, socioeconomic status, and BMI in relation to self-perception of overweight. Obesity. 2002;10(5):345-50.

38. McCabe RE, McFarlane T, Polivy J, Olmsted MP. Eating disorders, dieting, and the accuracy of self-reported weight. Int J Eat Disord. 2001;29(1):59-64.

39. Keith SW, Fontaine KR, Pajewski NM, Mehta T, Allison DB. Use of selfreported height and weight biases the body mass index-mortality association. Int J Obes. 2011;35(3):401-8.

40. Xie YJ, Ho SC, Liu ZM, Hui SS-C. Comparisons of measured and self-reported anthropometric variables and blood pressure in a sample of Hong Kong female nurses. PLoS One. 2014;9(9):e107233.

41. Flegal KM, Kit BK, Graubard BI. Bias in hazard ratios arising from misclassification by self-reported weight and height in observational studies of body mass index and mortality. Am J Epidemiol. 2017.

42. Dutton DJ, McLaren L. The usefulness of "corrected" body mass index vs. self-reported body mass index: comparing the population distributions, sensitivity, specificity, and predictive utility of three correction equations using Canadian population-based data. BMC Public Health. 2014;14(1):1.

43. Walsh MC, Trentham-Dietz A, Palta M. Availability of driver's license master lists for use in government-sponsored public health research. Am J Epidemiol. 2011;173(12):1414-8

44. Littenberg B, Lubetkin D. Availability, Strengths and Limitations of US state Driver's license data for obesity research. Cureus. 2016;8(3).

45. Ossiander EM, Emanuel I, O'Brien W, Malone K. Driver's licenses as a source of data on height and weight. Econ Hum Biol. 2004;2(2):219-27.

46. Willey P, Falsetti T. Inaccuracy of height information on driver's licenses. J Forensic Sci. 1991;36(3):813-9.

47. Morris DS, Schubert SS, Ngo DL, Rubado DJ, Main E, Douglas JP. Using state-issued identification cards for obesity tracking. Obes Res Clin Pract. 2015;9(1):87-91.

\section{Ready to submit your research? Choose BMC and benefit from:}

- fast, convenient online submission

- thorough peer review by experienced researchers in your field

- rapid publication on acceptance

- support for research data, including large and complex data types

- gold Open Access which fosters wider collaboration and increased citations

- maximum visibility for your research: over $100 \mathrm{M}$ website views per year

At $\mathrm{BMC}$, research is always in progress.

Learn more biomedcentral.com/submissions 